\title{
Peste des petits ruminants: A review
}

\author{
Abdul Kabir ${ }^{1}$, Dildar Hussain Kalhoro ${ }^{1 *}$, Shahid Hussain Abro ${ }^{1}$, \\ Muhammad Saleem Kalhoro ${ }^{1}$, Haider Ali Yousafzai ${ }^{1}$, Sheeba Shams ${ }^{1}$, \\ Ihsan Ullah Khan ${ }^{2}$, Ghulam Murtaza Lochi ${ }^{1}$, Muhammad Qasim \\ Mazari $^{1}$, Muhammad Waseem Baloch ${ }^{1}$, Arab Khan Lund ${ }^{3}$ and Mujeeb ur \\ Rehman Memon ${ }^{1}$ \\ 1. Faculty of Animal Husbandry and Veterinary Sciences Sindh Agriculture University, Tandojam-Pakistan \\ 2. Livestock and Dairy Development Department Khyber Pakhtunkhwa Peshawar, Pakistan \\ 3. Shaheed Benazir Bhutto University of Veterinary and Animal Sciences, Sakrand-Pakistan \\ *Corresponding author's email: drdildarkalhoro@gmail.com \\ Citation \\ Abdul Kabir, Dildar Hussain Kalhoro, Shahid Hussain Abro, Muhammad Saleem Kalhoro, Haider Ali Yousafzai, \\ Sheeba Shams, Ihsan Ullah Khan, Ghulam Murtaza Lochi, Muhammad Qasim Mazari, Muhammad Waseem \\ Baloch, Arab Khan Lund and Mujeeb ur Rehman Memon. Peste des petits ruminants: A review. Pure and Applied \\ Biology. Vol. 8, Issue 2, pp1214-1222. http://dx.doi.org/10.19045/bspab.2019.80063 \\ \begin{tabular}{llll}
\hline \hline Received: 17/01/2019 & Revised: 21/03/2019 & Accepted: 10/04/2019 & Online First: 18/04/2019 \\
\hline
\end{tabular}
}

\section{Abstract}

Peste-des-petits-ruminants (PPR) is a notifiable, contagious and economically important transboundary viral disease of small ruminant causing high morbidity and mortality. It belongs to negative-sense, single-stranded RNA paramyxovirus of genus Morbillivirus. PPR occurs in populations of immunologically naive sheep and goats, illness and death can be high as $>90 \%$. The virus is commonly found in developing countries, especially in tropical countries where the disease is widespread. After the eradication of the rinderpest virus, which is closely relate to PPRV of small ruminants contaminated with SRMV are diagnosed having pyrexia, oculo-nasal discharges, necrotizing and erosive stomatitis, gastroenteritis, diarrhea and broncho pneumonia, whereas, gross pathology, histological findings along with laboratory confirmation of specific virus antigen, antibodies, genome in the clinical samples through a variety of serological and molecular diagnostic tests can be useful. In addition there should be social economic surveys, disease hot spot recognition and identification of role of additional species in disease transmission. SRMV control may be achieved by confinement of contaminated animals, subtraction of theoretically tainted fomites with control at import and export of sheep with goats from contaminated areas. PPR can be controlled through mass vaccination program. In the future, the preparation of a marker vaccine with a robust companion test may assist in serosurveillance for the detection of infection in vaccinated animals to control the disease.

Keywords: Control; Epidemiology; Goat; Peste des petits ruminants; Sheep; Vaccination

\section{Introduction}

Peste des petits ruminants (PPRVirus) is quick spreading viral disease that affects sheep and goat. Goats may be more severely affected than sheep by PPRV infection [1]. During the acute stage of disease, animals show pyrexia $\left(40-42^{\circ} \mathrm{C}\right)$, despair, ulcers, vesicles erosion lying on tongue, smack its lips lacrimation, serous nasal discharge, abnormal breathing with coughing foulsmelling diarrhea and finally death [2]. In severe cases mortality and morbidity may 
ranges from 90 to $100 \%$ [3]. Clinical and pathological aspect of PPRV are closely resembles with rinderpest [4]. Moreover, PPR virus is a paramyxovirus of the Morbillivirus genus [5]. Morbillivirus genus include measles virus of humans, canine distemper of dogs, rinderpest virus of cattle and buffalo and the recently identified phocine distemper virus (PDV1) of seals [6].

\section{History}

In the early 1940's, it was a fatal disease of small ruminants with high mortality, first defined

as Peste-des-petits-ruminants (PPR) in the Ivory Coast (Cote d'Ivoire) in West Africa [7]. Similar syndrome was described in Dahomy (Benin) by Cathou (1944) under the name of "Peste des especes ovine etcaprine". The disease has been reported in Senegal and Ghana [8]. Furthermore, PPR Virus was initially isolated in Senegal in 1962 [9]. During 1950 a disease that affected mostly goats, was studied in Nigeria by Johnson and Ritchie in 1968. This disease was specified with variety of names including Stomatitis pneumoenteritis complex (SPC), Pseudorinderpest and Kata. Johnson and Ritchie in 1968 further proved that PPRVirus and SPC are the same disease [6]. Rowland and co-workers proved that the tentative infection of West African dwarf in goats by PPR and Kata were clinically and pathologically same [10]. PPR was controlled to West Africa, until a disease of small ruminants in the Sudan, which was originally identified as Rinderpest (RP) in 1972 [11]. After 10 year, disease was confirmed to be PPR [12]. It is possible that cases of severe rinderpest diagnosed in small ruminants in the past may be PPR. Whereas, PPRVirus was first time reported in sheep and goat including gazelles, ibex and gemsbok at Al Ain in the Arabian Gulf [13].

\section{Causative agent of PPR}

Peste Des Petits Ruminants (PPRV) belongs to the Morbillivirus genus of
Paramyxoviridae family [14]. Morbilliviruses are extremely contagious pathogens that cause destructive diseases of animal. The members of the genus morbillivirus are Rinderpest virus of cattle and buffaloes, Measles virus, Canine distemper virus, Phocid morbilliviruses and Porpoise distemper virus [15]. These viruses share the similar genome association though ribonucleic acid (RNA) [16]. The morbilliviruses are a closely associated group of important human and animal pathogenic viruses [5]. Morbillivirus is a non-segmented, distinct strand, pleomorphic, negative sense RNA virus measuring 200nm in diameter [17]. PPR is one of the longest sequenced Morbillivirus genomes comprising of 16 kilo base pairs [18].

\section{Geographical distribution}

PPR has progressively expanded to cover large regions in Africa, Southern Africa, Arabian Peninsula, Middle East and Asia. PPRV was first reported in 1942 (Ivory Cost), however it occurs mainly in the African and Asian countries.

There are four lineages of PPR virus variants; lineage I and II viruses in West Africa, lineage III in East Africa, Arabian and Southern India and lineage IV in the Middle East and Asia subcontinent [19].

Extensive geographic cover of PPR has been confirmed by the setting up of surveillance and control programs, raising awareness of local populations, the provision of sensitive and specific immunosorbent and molecular diagnostic techniques and the notification of disease emergence and epizootic outbreaks since 2004 by health authorities of the countries where it is considered as compulsorily notifiable disease. Notifications can be complemented by serological detection of antibodies and virological survey in enzootic and epizootic zones to identify the viral lineage involved, monitor the movements of the virus, understand spread 
factors and the impact of vaccination campaigns [20].

\section{Host range}

Peste des petitis ruminant (PPRV) is a zoonotic disease affecting small ruminants, but goats are affected more severely than sheep [21]. West African goats have been found to be more susceptible than European, and within the former group, the kids are more susceptible to the disease [22]. Cattle and pigs might be carrier to the virus without any clinical signs [23, 24]. It has been reported that the camels can be seroconvert to the PPRV [25]. Recent observations in Sudan suggested that the camels could be affected by PPR as they can show clinical expression of the disease and positive results were detected by serological tests that include RTPCR and cell culture [26, 27]. In one study, antibodies against PPR were detected in $3 \%$ of the 628 tested camels in Ethiopia [28].

\section{Transmission}

\section{Natural transmission}

Like other Paramyxovirus, PPRV cannot survive for long time outside the host [29]. Virus is excreted in nasal, oral and ocular discharges at the onset of pyrexia and in faeces at the onset of diarrhea. Animal from the incubation stage can infect other animals [30]. Spread of the disease can occur through interaction among susceptible animals. Infected animal and dirty equipment, oculonasal and oral discharge, loose faeces and grasping large quantity of the virus can cause transmission. The disease is transmitted between animals living in close contact by inhalation of aerosols which contain fine infectious droplets are produced by sneezing and coughing. Moreover, the disease can be spread by indirect contact through water, feed troughs and bedding contaminated with the virus [31].

\section{Experimental transmission}

Virus has been transmitted through different routes: nasal, oral, subcutaneous, intraocular, intratracheal and intravenoust [32]. The infective lymphoid tissue suspension is also used to infect goats and sheep after the propagation of the virus through three serial passages in goats. The tissue suspension failed to infect inoculated sheep [33]. While another transmission study indicated that the syndrome SPC (Stomatitis pneumo-enteritis complex) could pass from goat to goat by contact or by inoculation of susceptible goats with the infectious agent. They also reported that the disease could not be transmitted to cattle and rabbits inoculated via subcutaneous and cerebral routes [34]. Moreover, PPR is contagious due to the nature of the spread of the disease from kids to adult goats. Virus was inoculated from sheep to sheep and goats by using crude tissue material and tissue culture isolated from animals that died from Kata and SPC. Disease was transmitted through two passages in goats followed by one passage in cell culture then another one in goats $[35,36]$. Pigs can be infected with PPRV by inoculation or interaction by infected goat was impotent to spread the virus either to goats or pigs [37].

\section{Clinical signs}

Small ruminants are the main host of PPRV. PPR is measured in high fever, watery oculonasal discharge, gradually becoming muco purulent and stick parts of the eyelids, incubation period is 3 - 4 days [38]. Affected animals are characterized by tachypnoea and rapid increase during body temperature to $39.5-41^{\circ} \mathrm{C}$. Other symptoms include dilation of the nostrils, lips and tongue coughing [39]. Watery discharge is observed from nose, eyes and mouth, Fever is lay down surrounded by two days, mucous membranes and mouth, eye become marked, palate, dental pad, lips, inner aspect 10 cheeks with superior outside of tongue (Figure 1). The disease has per acute, acute and sub-acute syndromes [40]. In the majority of cases, PPR is an acute disease. The clinical signs in sheep are the same as in goats but generally less severe $[41,42]$. PPR 
is characterized by pyrexia, catarrhal irritation of the ocular and nasal mucous membranes, erosive stomatitis, conjunctivitis, gastroenteritis and pneumonia
[12]. Clinical signs and mortality significantly depend on the virulence of virus [43].
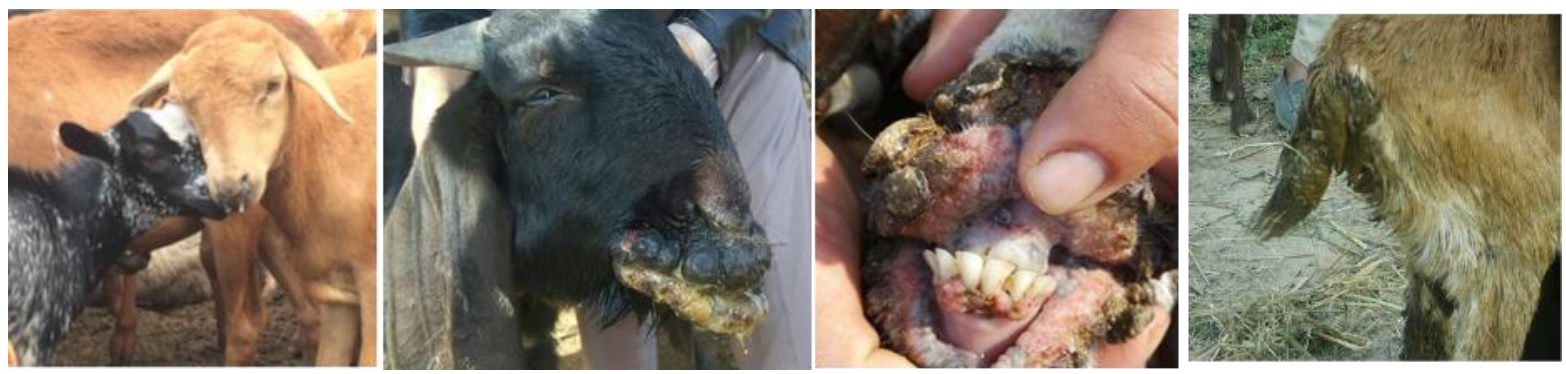

Figure 1. Represented goats; Nasal discharge, swollen, eroded lips, later mouth lesions, Diarrhoea

\section{Diagnosis}

Disease is tentatively diagnosed by clinical observations, post-mortem lesions and laboratory confirmation by several serological and molecular techniques including PPRV detection by specific antibody in serum, detection of viral antigens [2]. Young animals are severely affected. In per acute form animals show severe depression, loss of appetite, nasal and eyes discharge, diarrhea resulting in dehydration, pregnant animals may abort [44]. Post mortem examination revealed visible black red zones congestion of lungs, large and small intestines [40]. Severe lesions include congestion and "zebra stripes" large intestine. Erosive lesions can also arise in the vulva and vaginal mucous membranes. Bronchopneumonia through consolidation and atelectasis transpires are commonly observed [45].

The Laboratory confirmation of the disease is usually done by detecting virus or viral antigen, detection of genetic material from the virus and detecting antibodies against virus [46]. Current laboratory tests includes gene detection, Agar Gel Immuno-diffusion (AGID) Immunocapture enzyme-linked immunosorbent assay (ICE ELISA for antigen detection lateral flow device
(LFD;field test) conventional RT-PCR, Realtime RT-PCR, LAMP PCR (field test) [47]. Serological tests are virus neutralization and (c-ELISA) for antibody detection [17].

\section{Risk factors}

Age

Young animals of two years of age are affected. Older animals are much probable toward sero-positive of PPR than young one [48].

\section{Specie}

The goats are more susceptible than sheep as confirmed by various studies carried out in many parts of Pakistan [49]. PPR is also reported in the Sindh Ibex [50].

\section{Sex}

Ewes are more affected and positive for PPR than ram. This might be due to poor management system practiced in Pakistan [51]. Male animals are slaughtered in early stage of life while the female goat and sheep are kept live for breeding and milk [52].

\section{Season}

The climatic conditions highly affect the spread of PPR as in humid season PPR infection decreases due to restricted animal movement and availability of fodder with high nutritional status that causes enhance immune power against PPR disease [50]. Occurrence of PPR outbreaks may increase 
in months of December to February due to dry environment and dusty season along with reduced fodder presence in grazing area which supports the disease propagation [53]. Vaccines

Live attenuated homologous non thermostable PPR vaccines have been accessible in the market for certain time. They contain a variety of PPRV isolates, for example Nigeria 75/1 and Shun-gri/96, which are attenuated over serial passages in Vero cells [54]. The vaccines have been demonstrated to be highly effective and are suggested to provide lifelong immunity in both sheep and goats. These popular vaccines are used in many PPRV endemic countries [55]. Though until now no vaccine is available that can serologically distinguish vaccinated animals from diseased ones, a so called Differentiating Infected from Vaccinated Animals (DIVA) vaccine [56]. The available PPR vaccines do not support the DIVA principle. Possible DIVA vaccines based on recombinant viruses are good vaccine candidates. One vaccine based on recombinant adenoviruses has shown to be promising but has not undergone extensive or long term testing [57]. Thermo stable vaccines and other strategies for improving the stability of PPR vaccines are under study [58]. Some research has been done on synthetic short interfering RNAs (siRNAs) which might kill the virus while preserving the serological status of treated animals [59].

\section{Treatment}

There is no treatment for PPR but mortality rates may be decreased by use of broad spectrum antibiotics and antiparasiticides. Oxytetracycline and Chlortetracycline are suggested to inhibit secondary pulmonary infections [62]. Supportive care including fluid therapy can also decrease deaths due to dehydration and subsequent electrolyte imbalance [63]. Clinical cases of acute PPR can be adequately and successfully treated even in advanced cases particularly if treatment is started early [64].

Clinical cases of PPR disease in goats are preferably treated symptomatically by the use of broad spectrum antibiotics, intestinal sedatives and fluid therapy to treat pneumonia, diarrhoea and restore body fluid ionic balance [63]. Goats are treated with norfloxacin together with oral and $\mathrm{i} / \mathrm{v}$ administration of electrolytes and a liver detoxifying agent [65]. It was also observed that management of hyperimmune serum to animals incubating the disease or in the early stages of the disease before the start of diarrhea resulted in safety and recovery [66].

\section{Control and prevention}

Different control and preventive strategies can be used. At very first stage, separate the diseased animals from healthy animals to minimize the casual of transmission of PPR virus from diseased animals to healthy animals. Secondly slaughtering of apparent diseases animals and seropositive animals [67]. Furthermore, vaccination of animals is a good option to minimize the risk of incidence in healthy animal population [68]. Worldwide different immunization strategies against PPR has been used i.e. earlier immunization of small ruminants was done with lymph node and spleen materials containing contagious virus inactivated with 1.5-5 \% chloroform, attenuated tissue culture rinderpest vaccine (TCRV) but now PPR homologous vaccine is available which is prepared by a new freeze-drying process and addition of stabilizing agents [69].

\section{Conclusion}

Peste des petits ruminants is a severe, highly infectious and fatal viral disease of small ruminants all around the world including Pakistan and generally circulated in sheep and goat rearing areas. PPR transmission occurs through contact with infected animals. Goats are more susceptible than sheep. Clinical signs of PPR should be confirmed by laboratory testing. Vaccination of animals 
against PPR has a positive impact to control virus outbreak in the country. Thus, Mass vaccination program should be carried out in affected areas to reduce the PPR infection among sheep and goats.

\section{Authors' contributions}

Conceived and designed the experiments: A Kabir, DH Kalhoro \& SH Abro, Performed the experiments: A Kabir \& DH Kalhoro, Analyzed the data: MS Kalhoro, HA Yousafzai, MR Memon \& S Shams, Contributed materials/ analysis/ tools: GM Lochi, MQ Mazari, AK Lund \& MW Baloch, Wrote the paper: A Kabir \& DH Kalhoro.

\section{References}

1. Singh RP, Saravanan P, Sreenivasa BP, Singh RK \& Bandyopadhyay SK (2004). Prevalence and distribution of peste des petits ruminants virus infection in small ruminants in India. Rev Sci Tech 23(3): 807-819.

2. The Food and Agriculture Organization (1999). Recognizing Peste des Petitis Ruminants- A Field Manual. FAO Animal Health Manual No. 5.Rome: Food and Agriculture Organization of the United Nations. pp 1-27.

3. Dhar P, Sreenivasa BP, Barrett T, Corteyn M, Singh RP \& Bandyopadhyay SK (2002). Recent epidemiology of peste des petits ruminant's virus (PPRV). Vet Microbiol 88(2): 153-159.

4. Diallo A, Minet C, LeGoff C, Berhe G, Albina E, Libeau G \& Barrett T (2007). The threat of peste des petits ruminants: progress in vaccine development for disease control. Vaccine 25(30): 5591-5597.

5. Gibbs PJ, Taylor WP, Lawm MLP \& J Bryant (1979). Classification of peste des petits ruminants virus as the fourth member of the genus morbillivirus. Intervirology 11(5): 268-274.

6. Hamdy FM, Dardiri AH, Nduaka O, Breese SRJ \& Ihemelandu EC (1976). Etiology of the stomatitis pneumcenteritis complex in Nigerian dwarf goats. Canad $J$ Comp Med 40(3): 276-284.
7. Gargadennec L \& Lalanne A (1942). La peste des petits ruminants. Bull Serv Zoo AOF. 5: 15-21.

8. Mornet P, Orue J, Gilbert Y, Thiery G \& Sow M (1956). La peste des petits ruminants'en Afrique occidentale Françaiseet ses rapports avec la peste bovine. Revue d'Elevageet de Medecine Veterinaire des Pays Tropicaux 9(4): 313342.

9. Gilbert Y \& Monnier J (1962). Adaptation du virus de la peste des petitsruminants aux cultures cellulaires. Revue d'élevageet de medicine vétérinaire des pays tropicaux 15(4): 321-335.

10. Rowland AC, Scott GR, Ramachandran S \& Hill DH (1971). A comparative study of peste des petits ruminants and Kata in West African dwarf goats. Trop Anim Health Prod 3(4): 241-245.

11. Elhag AB (1973). A natural outbreak of rinderpest involving sheep, goats and cattle in Sudan. Bull Epi Dis Afr 21(4): 421-428.

12. Taylor W (1984). The distribution and epidemiology of Peste des Petits Ruminants. Prev Vet Med 2(1-4): 157-166.

13. Furley CW, Taylor TW \& Obi TU (1987). An outbreak of PPR in a zoological collection. Vet Rec 21: 443-447.

14. Murphy SK \& Parks GD (1999). RNA replication for the paramyxovirus simian virus 5 requires an internal repeated (CGNNNN) sequence motif. J Virol 73(1): 805-809.

15. McCullough SJ, McNeilly F, Allan GM, Kennedy S, Smyth JA,Cosby SL, McQuaid S \& Rima BK (1991). Isolation and characterisation of a porpoise morbillivirus. Arch Virol 118(3-4): 247252.

16. Barrett T (2001). Morbillivirus infections, with special emphasis on morbilliviruses of carnivores. Vet Microbiol 69: (1-2):313.

17. Libeau G, Prehaud C, Lancelot R, Colas F, Guerre L, Bishopand DH \& Diallo AA (1995). Development of a competitive ELISA for detecting antibodies to the 
peste des petitsruminants virus using a recombinant nucleoprotein. Res Vet Sci 58(1): 50-55.

18. Bailey D, Banyard A, Dash P, Ozkul A \& Barrett T (2005). Full genome sequence of peste des petit ruminant's virus, a member of the Morbillivirus genus. Virus Res 110 (1-2): 119-124.

19. Wang Z, Bao J, Wu X, Liu Y, Li L, Liu C, Suo L, Xie Z, Zhao W, Zhang W, Yang N, Li J, Wang S \& Wang J (2009). Peste des petits ruminants virus in Tibet, China. Emerg Infect Dis 15(2): 299-230.

20. Charbonnier G \& Laveissière G (2015). FAO and OIE Conference for the Control and Eradication of Peste des Petits Ruminants CIRAD April https://www.cirad.fr/extension/cirad_fr/de sign/cirad_fr/images/agriculturalresearch-for-development.png.

21. Nanda YP, Chatterjee A, Purohit AK, Diallo A, Innui K \& Sharma RN (1996). The isolation of peste des petitsruminants virus from Northern India. Vet Microbiol 51(3-4): 207-216.

22. Hymann CE, Bodjo SC, Danho T, Koffi MY, Libeau G \& Diallo A (2007). Early detection of viral excretion from experimentally infected goats with pestedes-petits ruminants virus. Prev Vet Med 78(1): 85-88.

23. Taylor WP (1979). Protection of goats against peste des petits ruminants with attenuated Rinderpest virus. Res Vet Sc 27(3): 321-324.

24. Lembo T, Oura C, Parida S, Hoare R, Frost L \& Fyumagwa R (2013). Peste des petits ruminants infection among cattle and wildlife in northern Tanzania. Emerg Infect Dis 19(12): 2037-2040.

25. Roger F, Yesus MG, Libeau G, Diallo A, Yigezu LM \& Yilma T (2001). Detection of antibodies of rinderpest and peste des petitsruminants viruses (Paramyxoviridae, Morbillivirus) during a new epizootic disease in Ethiopian camels (Camelusdromedarius). Rev Med Vet 152(3): 265-268.
26. Khalafalla AI, Saeed IK, Ali YH, Abdurrahman MB, Kwiatek O, Libeau G, Obeidaand AA\& Abbas Z (2010). An outbreak of peste des petits ruminants (PPR) in camels in the Sudan. Acta Trop 116(2): 161-165.

27. Kwiatek, O (2011). Asian lineage of peste des petitsruminants virus. Afr Emerg Infect Dis 17(7): 1223-1231.

28. Abraham G, Sintayehu A, Libeau G, Albina E, Roger F, Laekemariam Y, Abayneh D \& Awoke KM, (2005). Antibody seroprevalences against peste des petits ruminants (PPR) virus in camels, cattle, goats and sheep in Ethiopia. Prev Vet Med 70(1-2): 51-57.

29. Rossiter PB \& Taylor WP (1994). Peste des petits ruminants. Infectious Diseases of Livestock, Oxford University Press, Cape Town, South Africa.

30. Diallo A (2003). Control of peste des petits ruminants: classical and new generation vaccines. Dev Biol (Basel) 114: 113-119.

31. Abubakar M, Manzoor S \& Ali Q (2015) Evaluating the role of vaccine to combat peste des petits ruminants outbreaks in endemic disease situation. J Anim Sci Technol 57: 2.

32. Durtnell DR (1972). A disease of sokoto goats resembling "peste des petits ruminants". Trop Anim Health Prod 4(3): 162-164.

33. Durojaiye OA (1980). Brief notes on history, epizootiology and the economic importance of PPR in Nigeria. In: Proceedings of the International Workshop on Peste des Petits Ruminants, IITA, Ibadan, Nigeria, 24-26 September, 24-27.

34. Isoun TT \& Mann ED (1972). A stomatitis and pneumoenteritis Complex of sheep in Nigeria. Bull Epiz Dis Afr 20(2): 167-174.

35. Nduaka O \& Ihemelandu EC (1973). Observations on "pneumonia-enteritis complex" in dwarf goats in Eastern States of Nigeria. Bull Epiz Dis Afr 21(1): 87-98.

36. Dardiri AH, Boer DE \& Hamdy FM (1976). Response of American goats and cattle to peste des petits ruminants 
virus. Proceedings of the annual meeting of the American Association of Veterinary Laboratory Diagnosticians 19: 337-344.

37. Nawathe DR \& Taylor WP (1979). Experimental infection of domestic pigs with the virus of peste des petits ruminants. Trop Anim Health Prod 11(1): 120-122.

38. Roeder PL \& Obi TU (1999). Recognizing peste des petites ruminants: A field manual, FAO Animal Health Manual (5): 28.

39. Radostits OM, Gay CC, Hinchcliff KW \& Constable PD (2006). Veterinary medicine: a textbook of the diseases of cattle, horses, sheep, pigs and goats, 10th Ed. Saunders Elsevier, London. pp. 12421244.

40. Abubakar M, Jamal SM, Khan MA \& Ali Q. (2008). Peste des petits ruminants outbreak in small ruminants of Northern areas of Pakistan. Res J Vet Sci 1(1): 5661.

41. Durrani AZ, Kamal N, Mehmood N \& Shakoori AR (2010). Prevalence of peste des petits ruminants (KATA) in sheep and goats of Punjab. Pak J Zool 142(3): 211216

42. Dhand NK, Sharma CS, Sandhu KS, Sharma DR \& Singh J (2002) Outbreaks of peste des petits ruminants (PPR) in Punjab. Ind J Anim Sci 72(10): 853-854.

43. Office International des Epizooties (2012). Manual of Diagnostic Tests and Vaccines for Terrestrial Animals, $7^{\text {th }}$ Edition.

44. Abubakar M, Ali Q, Khan HA (2008). Prevalence and mortality rate of peste des petitis ruminant (PPR): possible association with abortion in goat. Trop Anim Health Prod 40(5): 317-321.

45. Bruning RA, Akerblom L, Klingeborn B \& Anderson J (2011) Improvement and development of rapid chromatographic strip-tests for the diagnosis of rinderpest and peste des petits ruminants viruses. $J$ Virol Method 174(1-2): 42-46.

46. Libeau G, Diallo A, Colas F \& Guerre L (1994). Rapid differential diagnosis of rinderpest and peste des petits ruminants using an immunocapture ELISA. Vet Rec134 (12): 300-304.

47. Munir M, Siddique M \& Ali Q (2009). Com-parative efficacy of standard AGID and precipitinogen inhibition test with mono-clonal antibodies based competitive ELISA for the serology of Peste des Petits Rumi-nants in sheep and goats. Trop Anim Health Prod 41(3): 413-420.

48. Zahur AB, Ullah A, Hussain M, Irshad H, Hameed A, \& Jahangir M (2011). Seroepidemiology of peste des petits ruminants (PPR) in Pakistan. Prev Vet Med 102(1): 87-92.

49. Abubakar M, Jamal SM, Arshed MJ, Hussain M \& Ali Q (2009). Peste des petits ruminants virus (PPRV) infection; Its association with species, seasonal variations and geography. Trop Anim Health Prod 41(7): 1197-1220.

50. Abubakar M, Arshed MJ, Hussain M \& Ali Q (2011). Evidence of Peste des Petits Ruminants in Serology of Sheep and Goats from Sindh Pakistan. Trans Emerg Dis 58(2): 152-156.

51. Jalees MM, Hussain I, Arshad M, Muhammad G, Khan QM \& Mahmood MS (2013). Occurrence of peste des petitis ruminants in five districts of Punjab, Pakistan. Pak Vet J 33(2): 165-169.

52. Khan HA, Siddique M, Arshad MJ, Khan QM, \& Rahman SU (2007). Seroprevalance of Peste des petitis ruminants (PPR) virus in sheep and goat in Punjab province of Pakistan. Pak Vet $J$ 27(3): 109-112.

53. Khan HA, Siddique M, Abubakar M, Arshad MJ \& Hussain M (2008). Prevalence and distribution of peste des petits ruminants virus infection in small ruminants. Small Rumin Res 79(2-3): 152157.

54. Saravanan P, Sen A, Balamurugan V, Rajak KK, Bhanuprakash V, Palaniswami KS, Nachimuthu K, Thangavelu, A, Dhinakarraj G, Hegde R \& Singh RK (2010). Comparative efficacy of peste des petits ruminants (PPR) vaccines. Biologicals 38(4): 479-85. 
55. Munir M, Zohari S, Saeed A, Khan QM, Abubakar M, LeBlanc N \& Berg M (2012). Detection and phylogenetic analysis of peste des petits ruminants virus isolated from outbreaks in Punjab, Pakistan. Transbound Emerg Dis 59: 8593.

56. Munir, M (2015). Peste des Petits Ruminants Virus: Springer, 10-29.

57. Herbert R, Baron J, Batten C, Baron M \& Taylor G (2014). Recombinant adenovirus expressing the haemagglutinin of peste des petits ruminants' virus (PPRV) protectsgoats against challenge with pathogenic virus; a DIVA vaccine for PPR. Vet Res 45(1): 24.

58. Riyesh $\mathrm{T}$, Balamurugan $\mathrm{V}$, Sen $\mathrm{A}$, Bhanuprakash V, Venkatesan G, Yadav V \& Singh RK (2011). Evaluation of efficacy of Stabilizers on the thermostability of live attenuated thermoadapted Peste des petits ruminants' vaccines. Virol Sin 26(5): 324337.

59. Sarkar J, Sreenivasa BP, Singh RP, Dhar P \& Bandyopadhyay SK (2003). Comparative efficacy of various chemical stabilizers on the thermostability of live attenuated peste des petits ruminants (PPR) vaccine. Vaccine 21(32): 47284735.

60. Diallo A (2004). Peste des petits ruminants. In: OIE Manual of Standards for Diagnostic Tests and Vaccines for Terrestrial Animals, 5th edition. Chapter 2.1.5. Office international des Epizooties, Paris, pp 114-122.

61. Wosu LO (1989). Management of clinical cases of peste des petits ruminants (PPR) disease in goats. Beitrag zür Tropischen
Landwirtschaft und Veterinarmedizin 27(3): 357-361.

62. Omamegbe JO \& Mecha MI (1984). Observations on the treatment of peste des petits ruminants (PPR) of goats. Bull Anim Health Prod Afr 32: 406-410.

63. Ayaz MM, Muhammad G \& Rehman MS (1997). Pneumo-enteritis syndrome among goats in Dera chazi Khan, Pakistan. Pak Vet J 17(2): 97-99.

64. Adu FD \& Joannis TE (1984). Serumvirus simultaneous method of immunization against peste des petits ruminants. Trop Anim Health Prod 16(2): 119-122.

65. Elsawalhy A, Mariner JC, Chibeu D, Wamwayi H, Wakhusama S, Olaho MW \& Toye P (2010). Pan African strategy for the progressive control of Peste des petits ruminants (Pan African PPR strategy). Bull Anim Health Prod Afr 58(3): 185-193.

66. Servan A, Keita D, Libeau G \& Albina E (2007). Control of ruminant morbillivirus replication by small interfering RNA $J$ Gen Virol 88(8): 2307-2311.

67. Braide VB (1981). Peste des petits ruminants. World Anim Rev 39:25-28.

68. Diallo A, Taylor WP, Lefevre PC \& Provost A (1989). Atténuation d'une souche de virus de la peste des petits ruminants: candidat pour unvaccin homologue vivant. Rev Elev Med Vet Pays Trop 42(3): 311-319.

69. Worrwall EE, Litamoi JK, Seck BM \& Ayelet G (2001). Xerovac: an ultra-rapid method for the dehydration and preservation of live attenuated rinderpest and peste des petits ruminants vaccines. Vaccine 19(7-8): 834-839. 